\title{
Perancangan Aplikasi Liva untuk Mengurangi Nomophobia dengan Pendekatan Gamifikasi
}

\author{
Pranatha Widya Pradana, Feby Artwodini Muqtadiroh, dan Amna Shifia Nisafani \\ Jurusan Sistem Informasi, Fakultas Teknologi Informasi, Institut Teknologi Sepuluh Nopember (ITS) \\ Jl. Arief Rahman Hakim, Surabaya 60111 Indonesia \\ e-mail: mafanineseventh@gmail.com
}

\begin{abstract}
Abstrak - Banyak aplikasi yang dapat mendukung proses komunikasi dan bersosial seperti sms, chat dan jejaring sosial. Namun sayangnya ini mengubah kebiasaan pengguna ketika berinteraksi. Sebelumnya setiap orang berkomunikasi melalui tatap muka, semakin berkembangnya teknologi akhirnya kebiasaan itu berubah. Banyak pengguna yang lebih sibuk dengan smartphone ketika berkumpul dengan keluarga, rekan atau kerabat. Aplikasi yang dapat mendekatkan orang yang jauh kini menjadi aplikasi Liva yang dapat menjauhkan orang yang dekat akibat ketergantungan menggunakan smartphone. Maka dalam tugas akhir ini penulis mengusulkan untuk mengembangkan aplikasi Liva, yang bertujuan mengurangi ketergantungan menggunakan smartphone sebagai salah satu solusi.

Untuk membantu mengurangi kebiasaan dalam menggunakan smartphone maka aplikasi dikembangkan menggunakan konsep gamifikasi. Konsep gamifikasi dipilih karena mampu membentuk pengalaman bermain sehingga dapat memacu dan memotivasi pengguna meraih hasil yang diinginkan. Dalam mengembangkan aplikasi dibutuhkan pengumpulan dan analisis kebutuhan pengguna. Kebutuhan pengguna didapat dari strategi gamifikasi yang selanjutnya dipetakan menjadi mekanik permainan dan storyboard. Untuk memvalidasi kebutuhan digunakan metode prototype agar target pengguna dapat memberikan feedback. Sebelumnya untuk mendapatkan penguji dilakukan screening test menggunakan panduan Google Venture Worksheet. Validasi dilakukan sebanyak dua kali terhadap 18 orang yang berbeda. Feedback penguji diharapkan mampu memberikan masukan untuk melakukan perubahan yang diperlukan hingga tujuan pengembangan tercapai. Maka hasil dari tugas akhir ini adalah desain storyboard gamifikasi aplikasi Liva.
\end{abstract}

Kata kunci: perancangan, ketergantungan smartphone, nomophobia, storyboard, prototype, gamifikasi.

\section{PENDAHULUAN}

$\mathrm{I}$ NFRASTRUKTUR internet yang semakin berkembang dengan cepat, menjadikan era informasi semakin terbuka. Dengan smartphone, kini setiap orang memiliki akses ke seluruh dunia dengan internet, menjadikan informasi cepat tersebar. Muncul dan berkembangnya perangkat lunak seperti chat, instant messenger, social network semakin memudahkan setiap orang untuk berkomunikasi, jarak kini bukanlah menjadi halangan.

Perkembangan teknologi informasi ini memiliki dampak dalam kehidupan manusia. Pew Internet dan American Life Project melakukan penelitian pada orang Amerika dalam menggunakan internet dan perangkat bergerak, pada tahun 2012 aktivitas penggunaan telepon selular berkembang selain mengirim pesan (80\%), yaitu mengambil gambar sebesar $82 \%$ dan mengakses internet sebesar 56\% [1]. Hanya dalam satu tahun terjadi peningkatan menjadi $91 \%$ untuk mengambil gambar dan 63\% untuk mengakses internet [2]. Begitu juga dalam kepemilikan dan penggunaan perangkat bergerak semakin luas. Pada Februari 2012 Nielsen Korea melaporkan 60\% pemilik smartphone adalah dewasa dan $84 \%$ pengguna smartphone adalah mahasiswa [3].

Dalam penggunaannya smartphone sangat membantu dalam berkomunikasi serta menjadi pendukung dalam melakukan aktivitas dengan aplikasi yang ada. Dengan smartphone saat ini orang dapat menjalin hubungan percakapan person-to-person dan sekaligus mengirim pesan. Beberapa orang memiliki kebiasaan menempatkan smartphone di meja agar mudah untuk dilihat dan jika interaksi percakapan secara tatap muka tidak cukup menarik, ada alternatif untuk mengalihkan perhatian [4]. Ketergantungan pada perangkat bergerak ini berdampak pada kehidupan sosial penggunanya. Sebanyak $33 \%$ pengguna yang bekerja, mengecek smartphone untuk email dan pesan pada malam hari [5]. Dalam penelitian yang dilakukan Oulasvirta ditemukan bahwa orang-orang mengecek smartphonenya sebanyak 34 kali sehari, bukan untuk keperluan memeriksa email atau menjalankan aplikasi yang lain, namun merupakan kebiasaan untuk menghindari rasa tidak nyaman [6]. Penelitian lain menyebutkan, kebanyakan siswa memulai harinya dengan mengecek laman jejaring sosialnya. Rata-rata jejaring sosial diakses selama 5 jam per hari dengan menggunakan smartphone [7].

Kebiasaan mengecek smartphone terlalu sering dapat mengakibatkan seseorang mengidap nomophobia. Nomophobia merupakan perasaan ketergantungan kepada smartphone dan mengakibatkan ketakutan berlebihan bila tidak berada disekitar atau memegang smartphone [8].

Peneliti dari Carnegie Mellon University mengemukakan paradoks bahwa internet, alat yang 
dirancang untuk menghubungkan manusia juga dapat menyebabkan pemutusan hubungan manusia dari keluarga dan kerabat [9]. Common Sense Media melakukan penelitian terhadap remaja berumur 13 hingga 17 tahun di Amerika mengenai dampak komunikasi digital terhadap kehidupan sosial. Sebanyak $45 \%$ remaja merasa frustasi terhadap temannya yang menggunakan smartphonenya ketika kumpul bersama. Dan $43 \%$ remaja berharap temannya dapat melepaskan smartphonenya untuk sementara waktu [10]. Meskipun menyukai teknologi baru dan perkembangannya untuk berkomunikasi, para remaja masih lebih menyukai berbicara bertatap muka secara langsung (49\%). Persentase tersebut paling tinggi dibandingkan berkomunikasi melalui pesan sebesar 33\%, jejaring sosial sebesar 7\% dan cara lainnya [10].

Dengan penggunaan smartphone yang cukup tinggi mengakibatkan sebagian orang lebih fokus pada perangkat bergeraknya dan mengabaikan orang lain disekitarnya ketika berkumpul. Dalam berkomunikasi secara langsung akan lebih baik jika setiap orang saling menghargai keberadaan orang di sekelilingnya. Agar setiap pengguna smartphone dapat menghargai orang lain maka kebiasaan sibuk menggunakan perangkat bergerak yang dimiliki ketika sedang bertatap muka harus dirubah. Salah satu solusinya yaitu dengan membangun aplikasi yang mampu meningkatkan kesadaran penggunanya untuk tidak menggunakan smartphone ketika sedang berkomunikasi secara tatap muka dengan orang lain. Dengan begitu aplikasi ini diharapkan mampu mendekatkan orang yang dekat.

Untuk memotivasi pengguna dalam menggunakan aplikasi diperlukan pemicu, salah satunya dengan konsep gamifikasi. Gamifikasi mampu memberikan motivasi serta pengalaman sehingga pengguna bisa terpacu untuk terus menggunakan aplikasi. Konsep gamifikasi diterapkan dengan menggunakan storyboard, sehingga pengembang memiliki acuan dalam mengembangkan aplikasi. Dalam storyboard terdapat mekanik serta skenario permainan [11].

Agar aplikasi yang akan dikembangkan dapat tepat menyelesaikan masalah maka diperlukan penggalian kebutuhan. Untuk menganalisis kebutuhan digunakan metode prototipe agar target pengguna dapat memberikan feedback. Dengan feedback tersebut diharapkan mampu memberikan masukan untuk melakukan perubahan yang diperlukan hingga tujuan pengembangan tercapai. Maka tugas akhir ini bertujuan untuk menggali kebutuhan aplikasi serta perancangan storyboard untuk gamifikasi pada aplikasi.

\section{TINJAUAN PUSTAKA}

\section{A. Addiction}

\section{Problematic Internet Use}

Problematic internet use sebelumnya dikenal dengan istilah internet addiction disorder [12]. Ini merupakan kelainan seseorang terhadap kebiasaannya mengakses internet dan menggunakan komputer [13].
Internet addiction disorder diusulkan oleh Ivan Goldberg, M.D. pada 1995 sebagai kelainan [14].

Saat ini banyak informasi yang tersedia di internet, hiburan yang dapat diakses melalui kebanyakan smartphone, tablet, laptop dan personal computer semua berpengaruh pada problematic internet use. Menghabiskan banyak waktu secara online menjadi masalah jika menyita waktu dalam kehidupan nyata, pada hubungan sosial dan pekerjaan [15].

\section{Information Deprivation Disorder}

Pada tahun 2011 dilakukan uji coba yang dinamakan Unplugged, volunter yang ikut tidak boleh mengakses email, pesan teks, facebook, twitter dan yang terkoneksi pada internet. Volunter berasal dari 12 universitas yang menghabiskan waktunya selama 24 jam untuk tidak mengakses komputer, ponsel, iPods, televise, radio dan juga koran, yang diperbolehkan hanya menggunakan telepon kabel dan membaca buku [16].

Dari uji coba tersebut disebutkan oleh Dr Gerodimos dari Bournemouth University bahwa partisipan merasa gelisah dan mencoba mengambil ponsel meskipun sebenarnya tidak dibawa. Teknologi telah mengubah kebiasaan seseorang dalam kehidupan sehari-hari. Dari partisipan yang ikut uji coba tersebut merasa sepi sehingga tidak nyaman dan canggung. Beberapa gejala yang dialami seperti memutus kebiasaan pada merokok atau kecanduan lainnya [16].

\section{Nomophobia}

Perkembangan dan penetrasi teknologi semakin meningkat, termasuk perangkat keras serta komunikasi virtual. Hal tersebut berdampak pada kebiasaan dan perilaku sehari-hari [17]. Perkembangan teknologi itu memberikan keuntungan seperti, memfasilitasi pertukaran informasi dan komunikasi.

Namun dengan perangkat teknologi saat ini seperti smartphone dan tablet yang mampu mendukung komunikasi justru menghilangkan faktor komunikasi faceto-face. Sehingga mampu mengganggu interaksi sosial dan isolasi sosial [17]. Dampak negatif lain dari perangkat teknologi adalah ketergantungan, salah satunya disebut nomophobia.

Di daerah Inggris Raya nomophobia (no mobile phobia) terus meningkat, dari 1000 orang yang disurvei $66 \%$ mengatakan takut kehilangan atau hidup tanpa ponsel [18]. Nomophobia merupakan perasaan ketakutan yang berlebihan saat kehilangan telepon genggam. Menurut sosiolog Zygmunt Baumant modernitas menyuguhkan aneka risiko, salah satunya alienasi manusia pada dirinya sendiri, sehingga orang menjadi terasing dengan dirinya [19].

LA Times juga melakukan survei dan menemukan bahwa 53\% responden menyebutkan khawatir bila tidak membawa telepon genggam. Dari hasil survei disebutkan bahwa perempuan lebih dominan mengidap nomophobia, $70 \%$ perempuan takut bila tidak membawa telepon genggam. Sedangkan laki-laki $60 \%$ mengaku nomophobia. Anak muda lebih banyak terkena 
nomophobia, sekitar $77 \%$ berumur 18 hingga 24 tahun [19]. nomophobia [17]:

Ciri-ciri dan karakteristik orang mengidap

a. Menghabiskan waktu menggunakan telepon genggam, mempunyai satu atau lebih gadget dan selalu membawa charger.

b. Merasa cemas dan gugup ketika telepon genggam tidak tersedia dekat atau tidak pada tempatnya. Selain itu juga merasa tidak nyaman ketika gangguan atau tidak ada jaringan serta saat baterai lemah.

c. Selalu melihat dan mengecek layar telepon genggam untuk mencari tahu pesan atau panggilan masuk. Oleh David Laramie ini disebut ringxiety. Ringxiety merupakan perasaan menganggap telepon genggam bergetar atau berbunyi.

d. Tidak mematikan telepon genggam dan selalu sedia 24 jam, selain itu saat tidur telepon genggam diletakkan di kasur.

e. Kurang nyaman berkomunikasi secara tatap muka dan lebih memilih berkomunikasi menggunakan teknologi baru.

f. Biaya yang dikeluarkan untuk telepon genggam besar.

\section{B. Gamification}

Gamifikasi merupakan konsep yang berasal dari domain media. Ini digunakan pada tahun 2008 tetapi baru mendapatkan pengakuan luas pada paruh tahun kedua 2010 ketika menjadi topik presentasi konfrensi dan diadopsi oleh industri. Definisi gamifikasi menurut Deterding adalah penggunaan elemen game design dalam konteks non-game [20], sedangkan menurut Huotari dan Hamari mendefinisikannya sebagai suatu proses untuk memberikan bentuk pengalaman bermain untuk mendukung penciptaan nilai secara keseluruhan [21].

Dalam membentuk sebuah permainan diperlukan game mechanics, game mechanics merupakan komponen yang digunakan game designer untuk menambahkan struktur seperti yang digunakan dalam sistem permainan. Beberapa game mechanics yang sering ada yaitu sistem virtual reward, seperti poin, lencana, mata uang virtual, level dan tantangan [22].

Membentuk sistem gamifikasi dimulai dari penentuan strategi gamifikasi. Pada strategi gamifikasi dijabarkan tujuan gamifikasi dan target pengguna terlebih dahulu. Output dari strategi gamifikasi menjadi acuan dalam menentukan mekanik game.

Unsur permainan akan menjadi bagian penting dimana orang akan dihargai dengan mendapatkan poin serta imbalan dalam menyelesaikan tantangan dengan unsur yang menyenangkan [23].

\section{Key Elements}

Beberapa elemen kunci dalam gamifikasi, adalah sebagai berikut [24]:

\section{Badges}

Unsur utama dalam gamifikasi adalah hadiah atau penghargaan bagi pemain setelah melakukan tantangan tertentu. Bentuk penghargaan bisa berupa badges, dalam aplikasi sosial dapat menunjukkan tingkat prestasi yang sudah dicapai.

2. Leaderboards

Orang biasanya ingin mengetahui tingkat pencapaian serta perbandingan dengan orang lain. Leaderboard bisa membantu untuk tahu tingkat pencapaian dengan orang lain sehingga menanamkan semangat kompetisi.

3. Point system \& Scores

Selain penghargaan ada cara lain untuk memotivasi dan mendorong perilaku yang diinginkan dengan mendapatkan poin dan kesempatan untuk memenangkan penghargaan. Pemain akan mendapatkan poin berdasarkan tingkat partisipasi.

4. Social Connection

Hubungan sosial memanfaatkan jaringan sosial dari pemain untuk menciptakan persaingan dan memberikan dorongan dalam bermain. Dengan hubungan sosial antar pemain, tingkat keterlibatan dan interaksi bisa ditingkatkan.

5. Levels \& Reputation

Dengan tingkat pencapaian yang diraih oleh pemain dapat meningkatkan reputasi pemain tersebut.

Setelah elemen kunci dihasilkan pada mekanik game maka selanjutnya adalah menentukan dimana elemen mekanik game tersebut diterapkan pada aplikasi. Storyboard menampilkan alur pengguna dalam menggunakan aplikasi. Alur pada storyboard menampilkan jalannya mekanik game dan fungsi aplikasi sehingga mampu memicu motivasi pengguna untuk berinteraksi.

\section{User Validation for Prototype}

1. Design Sprint Google

Design Sprint merupakan praktik dari metode yang digunakan oleh Google Venture dalam membantu para startup dalam membuat prototype secara singkat dan dapat segera dilakukan perbaikan. Google Venture adalah pemodal ventura milik Google yang berfokus pada pendanaan startup mulai dari tahap seed, venture sampai tahap perkembangan. Biasanya Google Venture berfokus pada startup teknologi, internet, perangkat lunak, perangkat keras dan bidang lainnya seperti healthcare, biotech dan sebagainya. Selain pada pendanaan Google Venture juga membantu dalam proses pengembangan sebelum dirilis.

Perancangan aplikasi Liva menggunakan salah satu metode testing pada design sprint Google untuk memvalidasi kebutuhan. Design sprint Google memiliki kelebihan untuk sesegera mungkin melakukan testing kepada target pengguna sebelum aplikasi memasuki proses coding. 


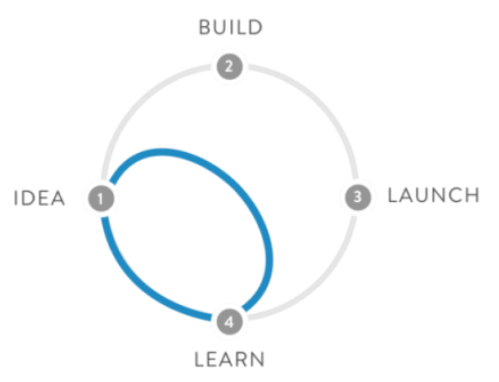

Gambar 1 Alur Engagement Loop

Design Sprint merupakan proses dalam mengukur kesuksesan sebuah produk melalui desain, prototyping dan testing ide kepada customer.

\section{Testing and User Research}

Google Ventures menggunakan worksheet untuk menentukan dan mengidentifikasi tester. Selain itu Google Ventures juga menggunakan worksheet untuk membuat dan memastikan research plan \& interview guide agar testingprototype mendapat feedback yang sesuai dengan tujuan awal identifikasi kebutuhan.

Dalam melakukan testing saran dari Jakob Nielsen, bahwa proses efektif melakukan testing aplikasi adalah pengujian terhadap 15 orang yang berbeda. Menurut Jakob Nielsen, usability problem sudah dapat dilihat dari pengujian terhadap 5 orang yang berbeda. Dengan pengujian terhadap 5 orang sudah dapat diketahui $85 \%$ usability problems. Pada gambar memperlihatkan hasil penelitian yang menunjukkan hal tersebut, dilakukan oleh Jakob Nielsen dan Tom Landauer.

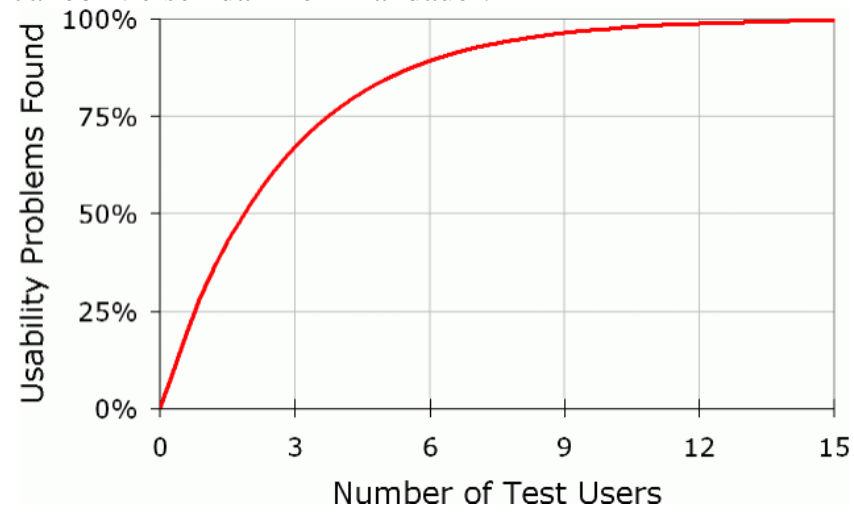

Gambar 2 Usability Problems Curves

Pada perancangan aplikasi Liva dilakukan dua kali testing dengan total 18 orang penguji. Dari setiap testing dilakukan evaluasi dengan mengumpulkan feedback para penguji yang sama. Hasil feedback itu akan dibandingkan dengan strategi gamifikasi sebagai bahan evaluasi dan perbaikan. Setelah evaluasi dan perbaikan pada tahap pertama maka akan dilanjutkan untuk dilakukan testing pada tahap kedua. Setiap hasil feedback akan dibandingkan dengan strategi gamifikasi sehingga tujuan aplikasi dapat tercapai.

\section{MetOdOLOGI}

Dari bagan metodologi tugas akhir dijelaskan dalam tabel mengenai proses input dan output serta tools/teknik yang digunakan dalam pengerjaan tugas akhir ini.
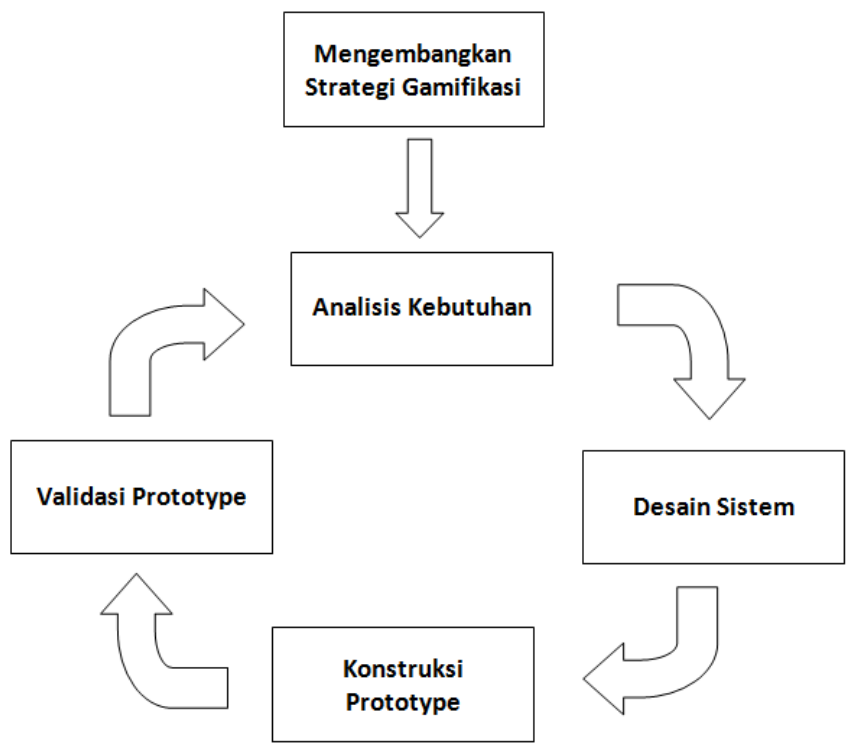

Bagan 1 Metodologi Tugas Akhir

Tabel 1 Proses Metodologi

\begin{tabular}{|c|c|c|c|}
\hline Aktivitas & Input & Output & $\begin{array}{l}\text { Tools / } \\
\text { Technique }\end{array}$ \\
\hline $\begin{array}{l}\text { Mengemba } \\
\text { ngkan } \\
\text { Strategi } \\
\text { Gamifikasi }\end{array}$ & $\begin{array}{l}\text {-Target } \\
\text { pengguna } \\
\text {-Permasalahan } \\
\text { pengguna } \\
\text {-Elemen } \\
\text { mekanik game }\end{array}$ & $\begin{array}{l}\text {-Strategi } \\
\text { gamifikasi } \\
\text {-Mekanik } \\
\text { game } \\
\text {-Storyboard }\end{array}$ & $\begin{array}{l}\text {-Tabel } \\
\text { strategi } \\
\text { gamifikasi } \\
\text {-Analisis } \\
\text { mekanik } \\
\text { game }\end{array}$ \\
\hline $\begin{array}{l}\text { Analisis } \\
\text { Kebutuhan }\end{array}$ & $\begin{array}{l}\text {-Strategi } \\
\text { gamifikasi } \\
\text {-Mekanik } \\
\text { game } \\
\text {-Storyboard }\end{array}$ & $\begin{array}{l}\text {-Kebutuhan } \\
\text { fungsional } \\
\text {-Kebutuhan } \\
\text { non } \\
\text { fungsional } \\
\text {-Dokumen } \\
\text { requirement } \\
\text { specification }\end{array}$ & $\begin{array}{l}\text {-Analisis } \\
\text { derivasi } \\
\text { kebutuhan } \\
\text { dari strategi } \\
\text { gamifikasi } \\
\text {-Enterprise } \\
\text { architect }\end{array}$ \\
\hline $\begin{array}{l}\text { Merancang } \\
\text { Prototype }\end{array}$ & $\begin{array}{l}\text {-Dokumen } \\
\text { requirement } \\
\text { specification } \\
\text {-Storyboard }\end{array}$ & $\begin{array}{l}\text {-Dokumen } \\
\text { deskripsi } \\
\text { perancangan } \\
\text { perangkat } \\
\text { lunak } \\
\text {-Desain dan } \\
\text { alur } \\
\text { purwarupa }\end{array}$ & $\begin{array}{l}\text { Entreprise } \\
\text { Architect }\end{array}$ \\
\hline $\begin{array}{l}\text { Membuat } \\
\text { Prototype }\end{array}$ & $\begin{array}{l}\text { Desain dan } \\
\text { alur prototype }\end{array}$ & $\begin{array}{l}\text { Prototype } \\
\text { user } \\
\text { interface }\end{array}$ & Prott \\
\hline Validasi & Prototype & $\begin{array}{l}\text { User } \\
\text { feedback }\end{array}$ & $\begin{array}{l}\text { Google } \\
\text { venture } \\
\text { worksheet }\end{array}$ \\
\hline $\begin{array}{l}\text { Kesimpula } \\
\text { n \& Saran }\end{array}$ & Hasil analisis & $\begin{array}{l}\text { Dokumen } \\
\text { tugas akhir }\end{array}$ & \\
\hline
\end{tabular}




\section{HASIL DAN PEMBAHASAN}

Proses pengujian dilakukan sebanyak dua kali. Pada setiap proses pengujian setiap hasil wawancara akan dikelompokkan sesuai kesamaan tanggapan. Berikut ini adalah hasil pengelompokan evaluasi tahap pertama

a. Penggunaan bluetooth yang justru akan menyulitkan dan membuat rumit.

Dari testing tahap pertama didapatkan bahwa calon pengguna merasa kurang nyaman menggunakan bluetooth untuk mengundang pengguna lain ke dalam event

b. Memperbolehkan pengguna lain bergabung saat event sudah berlangsung.

Pada tanggapan testing tahap pertama, beberapa calon pengguna mengatakan bahwa pada halaman home ketika melihat feeds dari teman tertarik untuk bergabung ke dalam event saat berlangsung. Namun aplikasi tidak dapat memperbolehkan pengguna masuk pada tengah event berlangsung.

c. Ketika terjadi disconnect saat event berlangsung nantinya apa yang akan terjadi.

Ada tanggapan dari beberapa calon pengguna yang bertanya bagaimana jika dengan bluetooth yang terkoneksi dan tiba-tiba pengguna pergi atau disconnect apa yang akan terjadi. Selain itu ada tanggapan lain dengan perlunya koneksi bluetooth serta data maka akan menguras baterai dan ketika smartphone mati maka pengguna akan keluar langsung dari event.

d. Terdapat perbedaan tanggapan terhadap konfirmasi respon dari aplikasi.

e. Ada tester yang memberikan tanggapan untuk menghilangkan konfirmasi saat ingin bergabung ke dalam event karena proses yang panjang justru membuat rumit. Namun ada beberapa tester yang ingin menambahkan konfirmasi dari sistem agar pengguna tidak salah melakukan aksi saat menggunakan aplikasi.

Kemudian dilakukan proses perbaikan dari tahap pertama ini. Dari hasil perbaikan maka dilakukan pengujian tahap kedua. Dan dilakukan proses pengelompokan sesuai hasil tanggapan. Berikut ini adalah hasil evaluasi tanggapan pada tahap kedua

a. Fitur penggunaan bluetooth dalam mengundang pengguna lain yang dekat justru membuat rumit. Selain itu penggunaan bluetooth tidak bisa dilakukan cross platform seperti IOS dengan Android.

b. Icon profil yang masih sulit dikenali oleh pengguna awal sebaiknya diganti agar pengguna bisa paham dengan sekali lihat.

c. Beberapa tester menyebutkan merasa kurang nyaman dengan penggunaan fitur with dan lokasi. Maka dengan penambahan pengaturan privacy pengguna bisa memilih.

d. Jenis update aktivitas yaitu create event pada pengembangan selanjutnya bisa ditambahkan untuk update aktivitas lain yang berhubungan dengan pilihan kegiatan bersama. e. Beberapa pengguna merasa kesulitan pada awal penggunaan aplikasi. Maka diawal setelah menginstall aplikasi pertama kali akan lebih baik diberikan introduction penggunaan aplikasi.

f. Pada bagian badges bisa ditambahkan keterangan agar pengguna tahu apa itu badges. Selain itu setiap badges juga dijelaskan cara untuk mendapatkan badges tersebut.

g. Beberapa ketertarikan pengguna adalah ingin melihat history dari event yang sudah diikuti. Maka dengan penambahan gallery pengguna bisa mudah menemukan foto event yang sebelumnya sudah diikuti.

Dari hasil analisis serta evaluasi maka tahapan selanjutnya adalah menyesuaikan dengan strategi gamifikasi agar hasil testing sesuai dengan tujuan awal. Tujuan pembuatan aplikasi ini adalah agar pengguna tidak mengakses smartphone ketika berkomunikasi tatap muka. Jika feedback uji coba sesuai dengan strategi gamifikasi maka perbaikan perlu dilakukan, namun apabila tidak terdapat kesesuaian maka bisa diabaikan atau dimasukkan sebagai saran untuk pengembangan selanjutnya. Dengan melihat kesesuaian dengan strategi gamifikasi maka perbaikan yang dapat dilakukan adalah sebagai berikut

Tabel 2 Hasil Evaluasi

\begin{tabular}{|c|c|}
\hline $\begin{array}{c}\text { Strategi } \\
\text { Gamifikasi }\end{array}$ & Evaluasi \\
\hline Challenges & $\begin{array}{l}\text { a. Penggunaan bluetooth bisa } \\
\text { diganti dengan memanfaatkan } \\
\text { nearby location memanfaatkan } \\
\text { geolocation agar lebih mudah } \\
\text { mengundang teman dan bisa } \\
\text { digunakan cross platform. }\end{array}$ \\
\hline Challenges & $\begin{array}{l}\text { b. Fitur with tetap digunakan karena } \\
\text { dalam sebuah event minimal } \\
\text { diikuti oleh dua pengguna. } \\
\text { Namun jika pengguna tidak } \\
\text { menghendaki ditampilkan maka } \\
\text { bisa ditambahkan pengaturan } \\
\text { privasi. }\end{array}$ \\
\hline - & $\begin{array}{l}\text { c. Fitur lokasi tidak harus selalu } \\
\text { dibagikan dan menjadi pilihan } \\
\text { pengguna. Ini dikarenakan } \\
\text { pembagian lokasi merupakan } \\
\text { privasi oleh pengguna dan bukan } \\
\text { merupakan strategi gamifikasi. }\end{array}$ \\
\hline Onboarding & $\begin{array}{l}\text { d. } \begin{array}{l}\text { Onboarding akan digunakan } \\
\text { sebagai tutorial penggunaan } \\
\text { aplikasi. }\end{array} \\
\end{array}$ \\
\hline Badges & 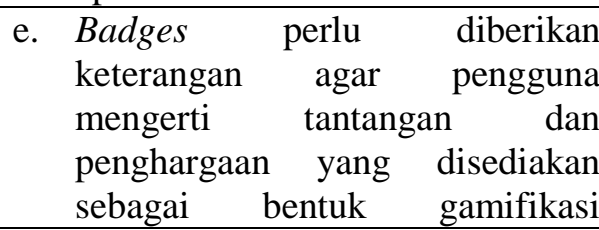 \\
\hline
\end{tabular}




\begin{tabular}{|c|c|c|}
\hline & & aplikasi. \\
\hline - & & $\begin{array}{l}\text { Penambahan photo gallery tidak } \\
\text { terlalu mendesak karena tidak } \\
\text { termasuk dalam strategi } \\
\text { gamifikasi. }\end{array}$ \\
\hline $\begin{array}{l}\text { Point, } \\
\text { Leaderboard }\end{array}$ & & $\begin{array}{l}\text { Terdapat saran skenario dari } \\
\text { tester, jika salah satu pengguna } \\
\text { ingin keluar terlebih dahulu dari } \\
\text { event. Pengguna yang ingin } \\
\text { keluar terlebih dahulu dapat ijin } \\
\text { dengan pengguna lain, namun } \\
\text { agar adil dalam permainan maka } \\
\text { pengguna yang keluar terlebih } \\
\text { dahulu perhitungan point berhenti } \\
\text { sampai menit pengguna tersebut } \\
\text { keluar serta tidak masuk dalam } \\
\text { urutan rangking pada } \\
\text { leaderboard. }\end{array}$ \\
\hline Challenges & h. & $\begin{array}{l}\text { Selain itu saran untuk } \\
\text { menambahkan permainan lain } \\
\text { yang bisa dilakukan bersama bisa } \\
\text { dipertimbangkan } \\
\text { pengembangan selanjutnya. untuk }\end{array}$ \\
\hline Challenges & & $\begin{array}{l}\text { Saran untuk menambahkan } \\
\text { informasi total pengguna } \\
\text { membuka atau unlock layar } \\
\text { smartphone juga bisa } \\
\text { dipertimbangkan } \\
\text { pengembangan selanjutnya. }\end{array}$ \\
\hline
\end{tabular}

Berikut ini adalah hasil dari perancangan aplikasi Liva

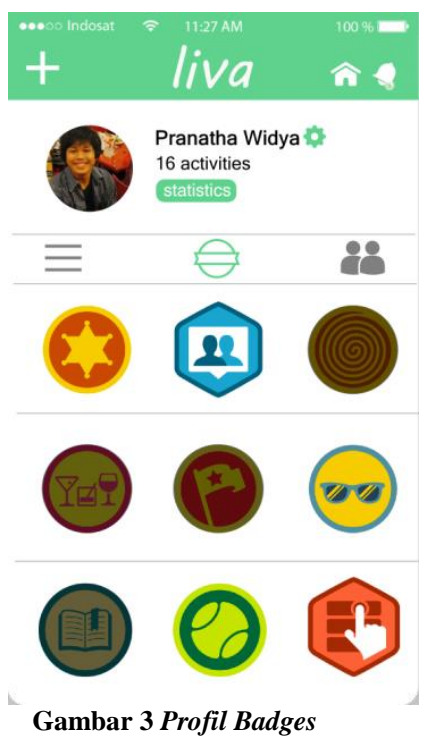

Pada halaman profil terdapat tab badges. Agar pengguna dapat mengetahui pencapaian dengan mudah maka badges akan ditampilkan dan dibedakan warnanya antara badges yang berhasil didapat serta yang belum. Saat pengguna melakukan tap atau menekan salah satu icon badges maka deskripsi dari badges tersebut akan ditampilkan.

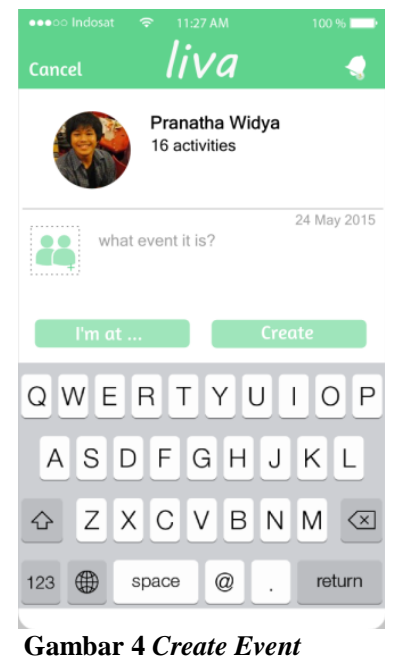

Gambar merupakan halaman yang bisa digunakan oleh pengguna untuk membuat event. Pengguna bisa menuliskan lokasi event berlangsung. Pengguna lain yang dapat diundang adalah pengguna yang lokasinya dekat saja.
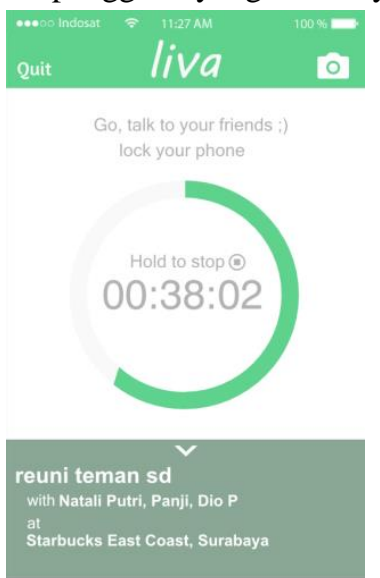

Gambar 5 Event Pada Aplikasi Sedang Berjalan

Gambar menunjukkan aplikasi Liva sedang berjalan dan memonitoring penggunaan aplikasi pada smartphone pengguna.

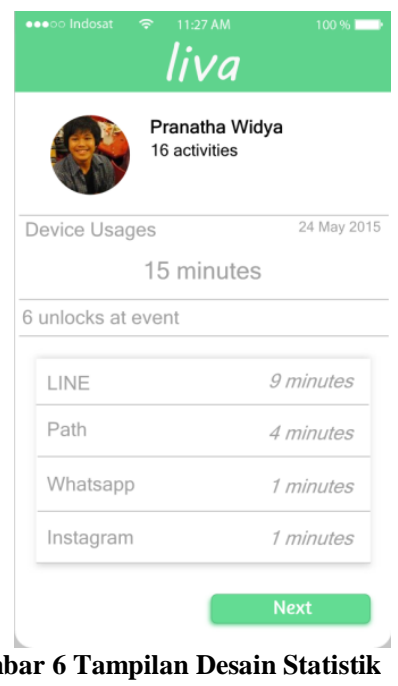


Gambar menampilkan halaman statistik pengguna selama mengikuti event. Pada statistik ini terdapat daftar aplikasi apa saja yang diakses selama mengikuti event.

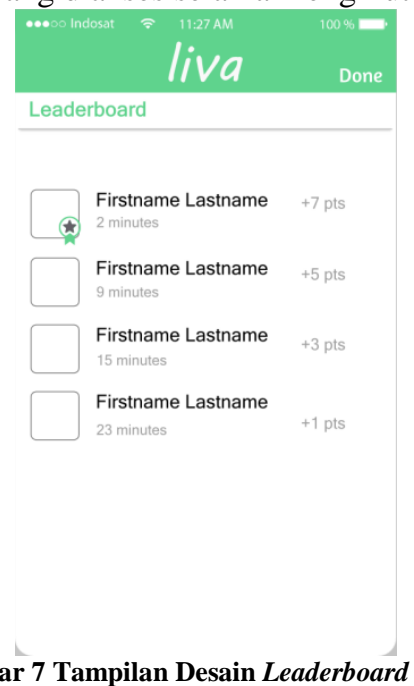

Gambar menampilkan halaman leaderboard setelah event selesai. Leaderboard menampilkan urutan pengguna yang mengikuti event, diurutkan berdasarkan pengguna yang paling sedikit mengakses smartphone.

Dalam pengerjaan Tugas Akhir ini konsep dan sistem aplikasi masih terdapat beberapa kekurangan yang bisa ditemukan. Berikut ini adalah kelebihan dan kekurangan konsep sistem aplikasi serta rencana pengembangan yang dapat diterapkan.

1. Kelebihan Konsep Aplikasi

1. Mampu memonitoring penggunaan aplikasi pada smartphone sehingga pengguna bisa mengetahui kebiasaan menggunakan smartphone.

2. Konsep aplikasi dengan bentuk sosial, familiar dan sudah dekat dengan pengguna.

3. Aplikasi menggunakan sistem gamifikasi yang bisa digunakan untuk mengarahkan pengguna mencapai goal pada aplikasi.

4. Sistem gamifikasi memberikan feedback dalam bentuk penghargaan kepada pengguna sehingga pengguna bisa termotivasi terus menggunakan aplikasi.

5. Sistem kompetisi dengan leaderboard dapat memicu pengguna untuk menahan untuk tidak membuka smartphone saat bertatap muka.

2. Kekurangan Konsep Aplikasi

1. Dalam konsep permainan aplikasi pengguna yang ingin bergabung ditengah permainan tidak bisa.

2. Konsep aplikasi perlu menggunakan koneksi internet sehingga aplikasi tidak akan berjalan tanpa koneksi internet.

3. Aplikasi hanya menghitung jumlah waktu penggunaan smartphone dan tidak bisa mengetahui kualitas interaksi.

4. Pengguna bisa membuat dua akun yang berbeda pada dua perangkat dan membuat aktivitas palsu.
5. Penggunaan nearby location dapat dimanipulasi dengan fake location gps pada perangkat pengguna.

6. Event hanya dapat dijalankan dengan minimal 2 pengguna, sehingga jika hanya terdapat dua pengguna saja dan salah satu pengguna tidak membawa smartphone maka aplikasi tidak dapat dijalankan.

7. Monitoring penggunaan smartphone tidak bisa memaksa seseorang untuk tidak mengakses smartphone.

8. Aplikasi tidak bisa mengetahui jarak antar pengguna ketika aplikasi sudah berjalan.

9. Aplikasi tidak bisa mendeteksi jika pengguna memiliki/menggunakan gadget lain.

10. Tidak bisa mendeteksi apakah pengguna berada dalam satu lokasi.

3. Rencana Pengembangan Ke Depan

1. Supaya pengguna lain dapat bergabung ditengah permainan maka untuk perhitungan leaderboard atau rangking bisa digunakan perhitungan persentase atau perbandingan dari total waktu pengguna mulai ikut beraktivitas dengan total waktu penggunaan aplikasi pada smartphone (sistem monitoring).

2. Memberikan pilihan untuk menonaktifkan smartphone saat event dimulai untuk setiap pengguna.

3. Menggunakan GPS untuk mendeteksi pengguna lain berada dalam satu lokasi

4. Membuat setting mock location pada perangkat android dan location lock dimana sistem yang akan menentukan current location bukan pengguna.

5. Menyediakan fitur sinkronisasi dua perangkat atau lebih. Sistem bisa memberikan reward bagi pengguna yang melakukan sinkronisasi.

\section{KESIMPULAN DAN SARAN}

Kesimpulan diambil secara menyeluruh pengerjaan Tugas Akhir ini mulai dari analisis strategi gamifikasi dan berdasarkan hasil dua kali testing yang dilakukan kepada 20 orang, berikut ini adalah kesimpulan yang didapat

1. Penggunaan bluetooth untuk mengundang teman dalam event tidak diminati oleh calon pengguna. Dengan menggunakan bluetooth calon pengguna merasa rumit dalam menggunakan aplikasi. Mayoritas masukan dari testing yang dilakukan adalah mengganti bluetooth dengan fitur nearby yang dipakai oleh aplikasi chatting yang ada.

2. Fitur monitoring penggunaan smartphone menjadi minat calon pengguna karena bisa mengukur aktivitas penggunaan smartphone saat berkumpul. Selain itu fitur berkompetisi dengan pengguna lain disebutkan oleh calon pengguna bisa membantu mengurangi aktivitas menggunakan smartphone.

3. Penghargaan dan pencapaian seperti point, badges diharapkan dapat lebih ditampilkan oleh calon 
pengguna. Dengan menampilkan penghargaan dan pencapaian yang didapatkan pengguna bisa meningkatkan perasaan bangga atas pencapaian yang dicapai.

4. Aktivitas pengguna lain menjadi tolak ukur lain pengguna dalam menggunakan aplikasi. Hal ini dapat dilihat dari minat pada saat testing yaitu calon pengguna ingin bisa mengetahui aktivitas dari pengguna yang sudah ditambahkan sebagai teman.

5. Maka dengan hasil masukan dan feedback dari testing yang sudah dilakukan, perbaikan dilakukan pada penambahan use case, desain aplikasi, sehingga kebutuhan fungsional juga mengalami perubahan, sedangkan kebutuhan non fungsional aplikasi tidak ada perubahan sama sekali.

Tabel 3 Kebutuhan Fungsional

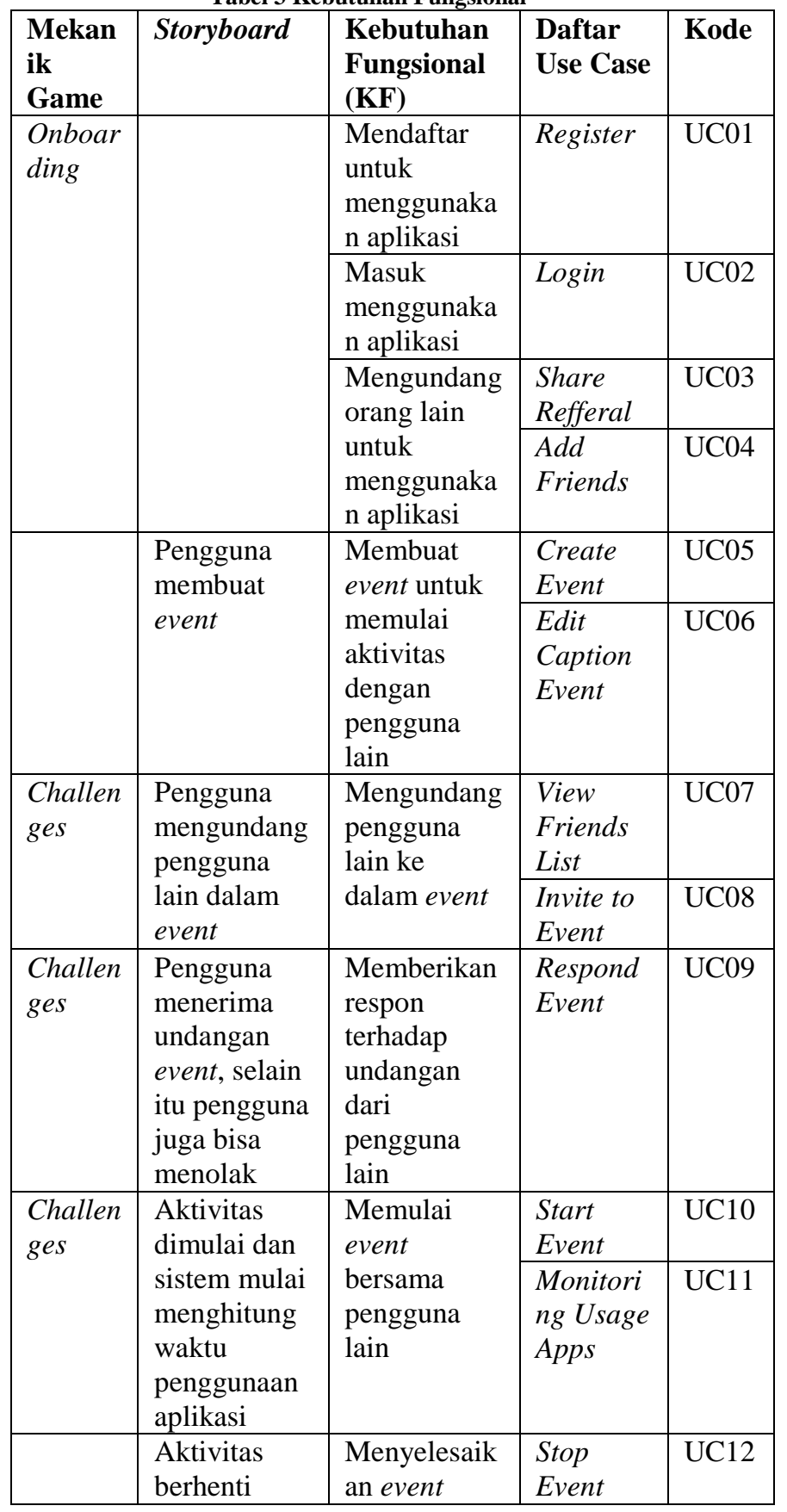

\begin{tabular}{|c|c|c|c|c|}
\hline $\begin{array}{l}\text { Mekan } \\
\text { ik } \\
\text { Game }\end{array}$ & Storyboard & $\begin{array}{l}\text { Kebutuhan } \\
\text { Fungsional } \\
\text { (KF) }\end{array}$ & $\begin{array}{l}\text { Daftar } \\
\text { Use Case }\end{array}$ & Kode \\
\hline & $\begin{array}{l}\text { ketika setiap } \\
\text { pengguna } \\
\text { setuju untuk } \\
\text { berhenti. } \\
\text { Kemudian } \\
\text { sistem akan } \\
\text { berhenti } \\
\text { menghitung } \\
\text { waktu } \\
\text { penggunaan } \\
\text { aplikasi. }\end{array}$ & $\begin{array}{l}\text { yang sudah } \\
\text { dimulai } \\
\text { bersama } \\
\text { pengguna } \\
\text { lain }\end{array}$ & & \\
\hline $\begin{array}{l}\text { Levelin } \\
g\end{array}$ & $\begin{array}{l}\text { Statistik } \\
\text { penggunaan } \\
\text { aplikasi pada } \\
\text { smartphone } \\
\text { ditampilkan } \\
\text { setelah } \\
\text { aktivitas } \\
\text { selesai. }\end{array}$ & $\begin{array}{l}\text { Menampilka } \\
\mathrm{n} \text { statistik } \\
\text { penggunaan } \\
\text { aplikasi } \\
\text { selama event }\end{array}$ & $\begin{array}{l}\text { Statistic } \\
\text { Usage }\end{array}$ & $\mathrm{UC13}$ \\
\hline \multirow[t]{2}{*}{$\begin{array}{l}\text { Levelin } \\
g\end{array}$} & & \multirow{2}{*}{$\begin{array}{l}\text { Menampilka } \\
\mathrm{n} \text { capaian } \\
\text { pengguna } \\
\text { dalam } \\
\text { menggunaka } \\
\mathrm{n} \text { aplikasi } \\
\end{array}$} & $\begin{array}{l}\text { View } \\
\text { Profile }\end{array}$ & UC14 \\
\hline & & & $\begin{array}{l}\text { View } \\
\text { Progress } \\
\text { Bar }\end{array}$ & UC15 \\
\hline $\begin{array}{l}\text { Leader } \\
\text { board }\end{array}$ & $\begin{array}{l}\text { Sistem akan } \\
\text { menghitung } \\
\text { jumlah } \\
\text { waktu } \\
\text { masing- } \\
\text { masing } \\
\text { pengguna } \\
\text { dan } \\
\text { mengurutkan } \\
\text { berdasarkan } \\
\text { pengguna } \\
\text { yang paling } \\
\text { sedikit } \\
\text { melakukan } \\
\text { aktivitas } \\
\text { dengan } \\
\text { smartphone. }\end{array}$ & $\begin{array}{l}\text { Menampilka } \\
\mathrm{n} \text { daftar } \\
\text { urutan } \\
\text { pencapaian } \\
\text { setiap } \\
\text { pengguna }\end{array}$ & $\begin{array}{l}\text { View } \\
\text { Leaderbo } \\
\text { ard }\end{array}$ & UC16 \\
\hline \multirow[t]{2}{*}{ Point } & \multirow{2}{*}{$\begin{array}{l}\text { Sistem akan } \\
\text { memberikan } \\
\text { point } \\
\text { berdasarkan } \\
\text { urutan } \\
\text { rangking } \\
\text { pengguna } \\
\text { dalam } \\
\text { beraktivitas. }\end{array}$} & $\begin{array}{l}\text { Menampilka } \\
\mathrm{n} \text { nilai yang } \\
\text { didapat dari } \\
\text { pencapaian } \\
\text { event }\end{array}$ & $\begin{array}{l}\text { View } \\
\text { Point }\end{array}$ & UC17 \\
\hline & & $\begin{array}{l}\text { Menjumlahk } \\
\text { an nilai yang } \\
\text { baru didapat } \\
\text { dengan point } \\
\text { sebelumnya }\end{array}$ & $\begin{array}{l}\text { View Exp } \\
\text { Point }\end{array}$ & UC18 \\
\hline Badge & & $\begin{array}{l}\text { Menampilka } \\
\mathrm{n} \text { hadiah } \\
\text { badge yang } \\
\text { didapat }\end{array}$ & $\begin{array}{l}\text { View } \\
\text { Badges }\end{array}$ & UC19 \\
\hline
\end{tabular}




\begin{tabular}{|c|c|c|c|c|}
\hline $\begin{array}{l}\text { Mekan } \\
\text { ik } \\
\text { Game }\end{array}$ & Storyboard & $\begin{array}{l}\text { Kebutuhan } \\
\text { Fungsional } \\
\text { (KF) }\end{array}$ & $\begin{array}{l}\text { Daftar } \\
\text { Use Case }\end{array}$ & Kode \\
\hline \multirow[t]{5}{*}{$\begin{array}{l}\text { Virtual } \\
\text { Gift }\end{array}$} & & \multirow{3}{*}{$\begin{array}{l}\text { Memberikan } \\
\text { apresiasi dan } \\
\text { tanggapan } \\
\text { pada } \\
\text { pengguna } \\
\text { lain }\end{array}$} & $\begin{array}{l}\text { View } \\
\text { Activities } \\
\text { Feeds }\end{array}$ & UC20 \\
\hline & & & Like & UC21 \\
\hline & & & Comment & UC22 \\
\hline & & $\begin{array}{l}\text { Menambahk } \\
\text { an foto event } \\
\text { yang sedang } \\
\text { berlangsung }\end{array}$ & $\begin{array}{l}\text { Add } \\
\text { photos }\end{array}$ & UC23 \\
\hline & & $\begin{array}{l}\text { Melakukan } \\
\text { pengaturan } \\
\text { pada } \\
\text { account } \\
\text { pengguna }\end{array}$ & Settings & UC24 \\
\hline
\end{tabular}

Sedangkan saran untuk pengembangan selanjutnya adalah :

1. Untuk mengembangkan aplikasi selanjutnya pengembang harus memperhatikan desain user interface karena sangat berpengaruh dalam penerimaan pengguna terhadap aplikasi.

2. Dalam pengembangan aplikasi versi selanjutnya atau menambahkan fitur baru harus dilakukan analisis penerimaan serta testing secara cepat agar aplikasi yang dibuat dapat diterima oleh target pengguna dan tujuan pembuatan aplikasi tercapai.

\section{DAFTAR PUSTAKA}

[1] Duggan, M. \& Rainie, L. (2012). Cellphone activities 2012. Pew Research Center's Internet \& American Life Project.

[2] Duggan, M. \& Smith, A. (2013). Cellphone activities 2013. Pew Research Center's Internet \& American Life Project.

[3] Park, N. \& Lee, Hyunjoo. (2014). Nature of Youth Smartphone Addiction in Korea. Konkurk University.

[4] Mengwei, B. (2012). Linking Psychological Attributes to Smart Phone Addiction, Face-to-Face Communication, Present Absence and Social Capital. The Chinese University of Hong Kong.

[5] Sarwar, M. \& Rahim, T. (2013). Impact of Smartphone's on Society. European Journal of Scientfic Research.

[6] Lee, Y., et al. (2013). The dark side of smartphoen usage: Psychological traits, compulsive behavior and technostress. Science Direct.

[7] Jeffrey, G., et al. (2012). Smartphone Application Usage Amongst Students at a South African University. IST-Africa.

[8] King, Anna Lucia Spear., et al. (2014). Nomophobia: Impact of Cell Phone Use Interfering with Symptoms and Emotions of Individuals with Panic Disorder Compared with a Control Group.
Clinical Practive \& Epidemiology in Mental Health vol 10.

[9] Kraut, R., et al. (1998). Internet Paradox: A social technology that reduces social involvement and psychological well-being. American psychologist, 53, 1017-1031.

[10] (2012). Social Media, Social Life: How Teens View Their Digital Lives. A Common Sense Media Research Study.

[11] (2012). White Paper Enterprise Gamification The Gen Y Factor. Bunchball.

[12] Moreno, Megan A., Jelenchick, Lauren A., Chistakis. (2013). Problematic Internet Use Among Older Adolescents: A Conceptual Framework. Computers and Human Behavior.

[13] Rosen, L. D. et al. (2012). iDisorder: Understanding Our Obsession with Technology and Overcoming Its Hold On Us. New York: Palgrave Macmillan.

[14] Beato, Greg (2010). Internet addiction: What once was a parody may soon be diagnostic.

[15] Saisan, Joanna., Smith, Melinda., Robinson, Lawrence. And Segal, Jeanne. (2014). Internet and Computer Addiction. Internet: http://www.helpguide.org/articles/addiction/intern et-and-computer-addiction.htm\#cyber, [Nov. 13, 2014]

[16] Gray, Richard. Facebook Generation Suffer Information Withdrawal Syndrome. Internet: http://www.telegraph.co.uk/technology/news/8235 302/Facebook-generation-suffer-informationwithdrawal-syndrome.html, Jan. 2, 2011 [Nov. 13, 2014]

[17] Bragazzi, Nicola Luigi. \& Puente, Giovanni Del. (2014). A Proposal for Including Nomophobia in the New DSM-V. Psychology Research and Behavior Management.

[18] Bingeman, Mitchell. Mobile Phone Withdrawal Symptoms on the Rise. Internet: http://www.theaustralian.com.au/technology/nomobile-phone-phobia-on-the-rise/story-fn4iyzsr1226290754991/, Mar. 7, 2012 [Nov. 6, 2014]

[19] Kurniawan, Sigit. Apakah Anda Seorang Nomophobia. Internet: http://www.themarketeers.com/archives/apakah-anda-seorangnomophobia.html, Feb. 22, 2012 [Nov. 6, 2014]

[20] Deterding, S., Dixon, D., Khaled, R. And Nacke, L. (2011). From Game Design Elements to Gamefulness: Defining “Gamification”. In Proceedings of the 15th International Academic MinTrek Confrence Envisioning Future Media Environments, p.9. ACM.

[21] Huotari, K. and Hamari, J. (2012). Defining Gamification: A Service Marketing Perspective. In Proceedings of the 16th International Academic MindTrek Confrence, p. 17, ACM, New York, USA.

[22] Chorney, Alan. (2012). Taking The Game Out Of Gamification. Dalhousie University, p. 2. 
[23] Maan, J. (2013). Social Business Transformation through Gamfication. Internationat Journal of Managing Information Technology, p. 10. 